RESENHAS

\title{
LITERATURA BRASILEIRA
}




\section{TINHORÃO, José Ramos. Domingos Caldas Barbosa: o poeta da viola, da modinha e do lundu (1740-1800). São Paulo: Ed. 34, 2004.}

José Américo Miranda

Universidade Federal de Minas Gerais

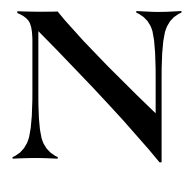

uma época fascinada por si mesma como a nossa, em que a quase totalidade dos interesses se volta para a contemporaneidade, um estudo sobre um poeta do período colonial tem a aparência de um evento inesperado. O livro de José Ramos Tinhorão sobre Domingos Caldas Barbosa é, a muitos títulos, uma obra importante. Em todos os detalhes, e até mesmo em suas falhas, o livro suscita interesse, comentário e debate. É um estudo que nos ensina muitas coisas e nos faz pensar outras; é, portanto, instigante e rico.

Domingos Caldas Barbosa tem sido, como diz o autor da obra, um "ausente da história". No tocante à história da literatura brasileira, essa ausência se deve, em parte, ao fato de o poeta, apesar de brasileiro e mulato, haver vivido e atuado em Portugal. Seus contemporâneos brasileiros o ofuscaram com suas auras de poetas, de amantes e de inconfidentes. Mas a importância de Caldas Barbosa é inegável, tanto no que diz respeito à poesia como à música popular. O livro de José Ramos Tinhorão vem, portanto, fazer-lhe justiça e corrigir uma falha em nossos estudos literários.

O livro se divide em duas partes: a primeira, mais extensa, trata do poeta e de sua trajetória biográfica; a segunda reúne e discute as informações disponíveis sobre a obra, traz alguns poemas inéditos e apresenta uma bibliografia do poeta.

Na primeira parte, pela ausência de informações precisas e detalhadas 
acerca do autor estudado, o estudioso fez um notável esforço para a reconstituição de seu ambiente e de sua trajetória. A vida no Rio de Janeiro setecentista e as condições em que aí viveu o poeta antes de partir definitivamente para Portugal foram cuidadosamente reconstituídos. São narrados de modo sucinto, mas de forma interessante e capaz de despertar grande interesse no leitor, a juventude de Caldas Barbosa e sua experiência militar, por ocasião da expedição ao sul, nas lutas portuguesas pela conservação da província do Sacramento. Igualmente interessantes são as narrativas dos primeiros tempos do poeta em Portugal, em Coimbra e Lisboa. Grande parte das informações sobre sua trajetória, à falta de documentos, o estudioso extraiu do poema autobiográfico "A doença" publicado em Lisboa em 1777 e reproduzido por Adriana de Campos Rennó em tese apresentada à Faculdade de Ciências e Letras da Universidade Estadual Paulista Júlio de Mesquita Filho, de Assis, São Paulo, em 2001 (fonte utilizada pelo autor).

Nos anos da maturidade, sob a proteção dos irmãos Vasconcelos e Sousa, suas atividades de músico, de talentoso improvisador, de autor teatral e de pretendente a um cargo eclesiástico foram objeto de estudo, e a credibilidade das fontes de informação criticamente avaliada. As "Quartas-Feiras de Lereno", como se chamavam as reuniões da Nova Arcádia, de que foi o criador, por onde ruidosamente passou o poeta Bocage, apresentam-nos o poeta dos salões. E, além disso, foi Caldas Barbosa o "lançador dos gêneros musicais populares da modinha e do lundu de sua terra (o Brasil), cantados com acompanhamento de viola." (p. 66) Dessa atividade de músico resultou a específica contribuição do poeta ao seu século.

$\mathrm{Na}$ segunda parte do livro, o autor publica dois sonetos inéditos, cujos autógrafos foram localizados por ele, assim como uma epístola apógrafa. Esses três poemas são apresentados em fac-símiles, acompanhados de leitura - que ainda será objeto de comentário da responsabilidade do autor. Outro capítulo dá notícia de outros apógrafos do poeta e apresenta, transcritas (infelizmente sem os facsímiles), todas as composições que não constam da Viola de Lereno, a mais conhecida e publicada das obras do poeta (cuja última edição, pela Editora Civilização Brasileira, data de 1980). O pesquisador apresenta, ainda, um levantamento completo das composições de Caldas Barbosa no Almanaque das Musas - publicação que reúne as 
produções dos poetas da Nova Arcádia, de 1790 a 1793 -, um elenco de obras que lhe são atribuídas - cuja legitimidade é discutida -, e, por fim, uma bibliografia geral do poeta.

O livro apresenta reproduções fac-similares de diversas edições raras da obra de Caldas Barbosa. O cuidado com que o livro foi preparado e com que a pesquisa foi feita justifica, ainda, algumas observações.

Há muito que aprender com este livro, para além da matéria nele tratada. A certa altura, no capítulo em que faz o levantamento das obras de Caldas Barbosa publicadas no Almanaque da Musas, depois de citar Inocêncio Francisco da Silva, que registrara o fato de a maior parte das poesias dessa publicação ser de autoria do poeta brasileiro, diz o autor:

Pois, como quase um século e meio após essa observação de Inocêncio, a raridade do Almanaque das Musas (ou o desinteresse dos historiadores de literatura brasileira) ainda continuava a manter tal lacuna [no conhecimento das obras de Caldas Barbosa], o autor deste livro tomou a si a realização de uma primeira tentativa de identificação do que pertence a Domingos Caldas Barbosa nos quatro tomos dessa coletânea da produção indistinta dos poetas componentes da Nova Arcádia, de Lisboa, de 1790 a 1793. (p.201)

O que espanta nessa avaliação é a possibilidade, apontada entre parênteses, de o atual estado de desconhecimento das obras de tão importante poeta dever-se ao descaso dos historiadores da Literatura Brasileira. No estágio atual dos estudos literários no Brasil, com um sistema de cursos de pós-graduação já extenso e de alta qualificação, é imperdoável que alguém possa (e com tanta razão e evidência!) afirmar algo assim. É preciso que não percamos a oportunidade de refletir sobre os caminhos da pós-graduação em estudos literários no Brasil, tão interessada nas teorias da moda e tão desinteressada de seu objeto de estudo. Essa situação nos lembra o que escreveu Nelson Rodrigues, em suas confissões, sobre o que se faz no Brasil:

Os atores não representam, e também o romancista não faz romance, nem o poeta, poesia, nem o pintor, pintura, nem o cineasta, filme. Sim as coisas devem ser feitas, ninguém as faz." 1

${ }^{1}$ RODRIGUES, [s.d.], p. 245. 
Ao que poderíamos acrescentar, a julgar pelo caso Caldas Barbosa, e apenas a título de propor matéria à reflexão: nem o historiador literário faz história, nem os pesquisadores de literatura estudam literatura.

É louvável o esforço do autor para cumprir e executar tarefas que caberiam aos historiadores da Literatura Brasileira e a outras áreas específicas do conhecimento. Esse esforço, no entanto, nem sempre deixa satisfeitos os leitores. Nos poemas inéditos de Caldas Barbosa, o sistema de transcrição do manuscrito não é uniforme. Ao que tudo indica, pretendeu o autor realizar uma transcrição diplomática, fiel ao manuscrito, pois não acentuou palavras, não modernizou ortografia, não separou palavras que vêm unidas no manuscrito, não alterou a pontuação, etc. Entretanto, só para dar um exemplo, "sauzentou" foi transcrita com "s" no lugar do "z": "sausentou". Como essa, há inúmeras falhas nas transcrições, além de importantes erros de leitura. Na transcrição do soneto "A El Rey N. Senhor”, para, também no caso dos erros, ficarmos apenas num exemplo, há pelo menos um erro importante em cada estrofe: na primeira, a expressão "Osga do aseio" é transcrita como "Osga do oficio"; na segunda, "Mecenas" é lido como "Neunas"; na terceira, "me sinto" está no lugar de "me sinta"; e na quarta, no último verso, "tornado" foi lido como "xamado". Como se vê, o autor não é lá muito bom leitor de manuscritos. Ele se desculpa (e merece ser desculpado), afirmando ser a "leitura de nossa responsabilidade". A mesma desculpa antecede as transcrições das dez composições que vêm no décimo quarto capítulo do livro, das quais não há reprodução fac-similar dos manuscritos. E na ausência dos manuscritos o texto transcrito torna-se inútil, já que a leitura não é confiável.

É surpreendente a ocorrência desses problemas em pesquisador tão rigoroso, que chega ao ponto de assinalar, em nota de rodapé, a impropriedade da tradução, num texto de De La Flotte, do francês guitare por "violão" (Afonso E. Taunay) e por "guitarra" (Jean Marcel Carvalho França) - quando o instrumento de que se trata, segundo o autor, é "a tradicional viola portuguesa-brasileira” (p. 2122 , nota 10 ). Com a mesma seriedade e interesse pelo detalhe, aponta o autor o sentido correto do adjetivo "astreal", num verso em que o poeta narra seu encontro com seus protetores, os irmãos Vasconcelos, ambos ocupantes de cargos na magistratura - o que não faz sem anotar, em rodapé, que Adriana de Campos Rennó, autora da mencionada tese de doutorado 
sobre Caldas Barbosa, errara, pois "comete neste ponto o engano de julgar a palavra astreal sem sentido no verso 'a dura lida da astreal balança', por não ter percebido que o poeta se referia à deusa grega Astréa, da Justiça, a cujo serviço andavam os irmãos Vasconcelos em 'dura lida'." (p. 44, nota 40)

Há, também, no livro diversas falhas de revisão. Delas apontaremos apenas duas: a marquesa de Alorna, d. Leonor de Almeida, por um erro na data de nascimento, morreu mais que centenária (p. 65) e o célebre terremoto de Lisboa, também por um erro de data, foi antecipado de cinco anos (p. 53).

$\mathrm{E}$, por fim, é digna de registro uma denúncia do autor, também feita em rodapé. Transcrevemos na íntegra a nota 100, da página 96:

A coleção manuscrita intitulada 'Cantigas de Lereno Selinuntino' consta do acervo da biblioteca do Gabinete Português de Leitura do Rio de Janeiro sob a indicação de catálogo C. Barboza Cantigas R. E. P. L. Armário 6A 25. O autor deste livro, após várias tentativas de obter vista dos manuscritos junto a funcionários da biblioteca do Gabinete Português de Leitura (o que só lhe foi concedido em fins de 2000, com permissão para cópia apenas manual), conseguiu fotocópias da coleção completa em novembro de 2001, em Lisboa, por gentileza especial do musicólogo Manuel Morais, professor da Universidade de Évora. Segundo Manuel Morais, as cópias recusadas ao pesquisador brasileiro, no Rio de Janeiro, foram por ele conseguidas mediante o simples envio de solicitação por carta datada de Lisboa.

É inacreditável e inadmissível que no Brasil os pesquisadores sejam tratados desse modo, enquanto pesquisadores vindos do exterior têm fácil acesso a qualquer arquivo. E podemos garantir que isso não acontece somente no Gabinete Português de Leitura. Prestamos ao autor, aqui, a nossa solidariedade e somamos ao dele o nosso protesto.

\section{Referência bibliográfica}

RODRIGUES, Nelson. A cabra vadia (Novas confissões). Rio de Janeiro: Eldorado, [s.d.]. 